\title{
Effects of Chewing Frequency on Cerebral Blood Flow and Cognitive Function
}

\section{Saya Natsui ${ }^{*}$, Megumi Sato ${ }^{2}$, Tomomi Yokoyama3 ${ }^{3}$ Hiromi Inaba ${ }^{4}$, Naomi Kuboyama5, Kenichi Shibuya ${ }^{4}$}

${ }^{1}$ Graduate School of Health and Welfare, Niigata University of Health and Welfare Graduate School, Niigata, Japan

${ }^{2}$ RESCO Corporation, Tokyo, Japan

${ }^{3}$ WELCIA YAKKYOKU CO., LTD., Niigata, Japan

${ }^{4}$ Department of Health and Nutrition, Niigata University of Health and Welfare, Niigata, Japan

${ }^{5}$ Osaka University of Commerce, Osaka, Japan

Email: *whm19001@nuhw.ac.jp, carbohydrate56g@gmail.com,wha12041@nuhw.ac.jp, inaba@nuhw.ac.jp,

kuboyama@daishodai.ac.jp, kenichi.shibuya1972@gmail.com

How to cite this paper: Natsui, S., Sato, M., Yokoyama, T., Inaba, H., Kuboyama, N. and Shibuya, K. (2020) Effects of Chewing Frequency on Cerebral Blood Flow and Cognitive Function. Journal of Behavioral and Brain Science, 10, 287-295.

https://doi.org/10.4236/jbbs.2020.107018

Received: March 13, 2020

Accepted: July 13, 2020

Published: July 16, 2020

Copyright $\odot 2020$ by author(s) and Scientific Research Publishing Inc. This work is licensed under the Creative Commons Attribution International License (CC BY 4.0).

http://creativecommons.org/licenses/by/4.0/

\begin{abstract}
The purpose of the present study was to examine the effect of the frequency of mastication on cerebral activation and task scores for computational tasks. Eleven healthy subjects participated in the present study (nine women, two men). Subjects carried out the Uchida-Kraepelin Test for $15 \mathrm{~min}$ before and after chewing tasteless gum for five minutes. The oxygenation of the left prefrontal cortex was monitored by near-infrared spectroscopy during the computational tasks. Task scores did not differ significantly according to chewing frequency ( $p>0.05)$. Conversely, the oxygenation value measured after mastication at a chewing frequency of 110 times/minute $(\mathrm{Hz})$ was significantly higher than that observed before mastication $(p<0.05)$. Meanwhile, before and after levels of oxygenation did not differ significantly for chewing frequencies of $30 \mathrm{~Hz}$ and $70 \mathrm{~Hz}$ ( $\mathrm{p}>0.05$ for both). The results of the present study suggest that tasteless mastication does not enhance calculation performance, while a high mastication frequency demonstrates an influence on oxygenation. However, our study indicates that chewing tasteless gum per se does not increase cognitive performance.
\end{abstract}

\section{Keywords}

Mastication, Frequency, Brain Activity, Uchida-Kraepelin Test, Near-Infrared Spectroscopy 


\section{Introduction}

The elderly population is expanding rapidly in Japan. The number of people with dementia will reach seven million in 2025 because of the increase in the elderly population [1]. Being common in older people and major causes of morbidity and mortality, cognitive impairment and dementia resulting from age-related decline is of substantial public health concern [2]. Attention has been focused on brain atrophy as the cause of dementia and the fact that decreased cerebral blood flow may lead to brain tissue damage [3]. Mastication is an activity that increases brain activity and enhances cognitive function [4] [5]. Mastication may activate the motor, somatosensory, and supplementary motor areas, as well as the cerebellum, among others. Stimulation is transmitted to the cerebral blood vessels via the trigeminal afferent nerve to release vasodilated substances [6]. Numerous studies were conducted regarding the effects of epilepsy on cognitive function. Researchers reported that waking up due to mastication [7] [8] [9] results in an increase in energy consumption [10] [11]. Re-searchers also reported that performance reaction time [12] and working memory may also improve [13] [14] [15] because of mastication. Other reports involving neuro-scientific measurements indicate that mastication increases brain activity [5] and shortens cognitive processing time (e.g., the P300 wave of event-related potential after mastication [4]). In addition, studies that regard mastication as a movement that mobilizes neurons throughout the brain also exist [16] [17] [18]. Generally, exertion of force during exercise and an increase in exercise frequency exhibits a vast influence on brain activity [19] [20] [21] [22]. Furthermore, researchers reported that exercise improves cognitive function and that this improvement depends on exercise intensity [23]. It is also known that brain activity increases with exercise frequency [19] [21] [22]. It is likely that brain activity is affected by mastication frequency, potentially affecting cognitive function. Researchers also reported that blood flow in the common carotid artery rises with an increase in mastication frequency [24]. However, to date, no report exists on the relationship between chewing frequency and cognitive function, particularly brain activity.

The purpose of the present study was to examine how brain activity during a computational task is influenced by chewing movements with an emphasis on increasing chewing frequency. Therefore, we studied changes in chewing frequency and measured changes in cerebral oxygenation by near-infrared spectroscopy (NIRS) in the prefrontal cortex during the computational task before and after chewing.

\section{Methods}

\subsection{Subjects}

The study subjects comprised of 11 healthy people (two males and nine females; mean age, $20.545 \pm 4.591$ years). None of the subjects presented with neurological or psychiatric disease. In addition, informed consent was obtained from all 
subjects. Ethical approval was obtained from the Niigata University of Health and Welfare Ethics Committee (No. 17619-150909).

\subsection{Uchida-Kraepelin Test}

The Uchida-Kraepelin Test (U-K Test) involves continuous calculations and can be used to measure mental fatigue. The U-K Test is widely used in the fields of clinical psychology, psychiatry, and occupational mental health. In the present study, subjects were instructed to add random numbers printed on paper for 15 min. After taking a rest, they were instructed to repeat the task for another 15 min. Subjects were instructed to calculate as many sums as possible.

\subsection{Near-Infrared Spectroscopy (NIRS)}

In the present study, NIRS (NIRO-200, Hamamatsu Photonics, Hamamatsu, Japan) was used to monitor changes in brain oxygenation in the left prefrontal cortex. The NIRS optode consists of a light source with a semiconductor laser and a photodetector. This device detects changes in the concentration of oxygenated hemoglobin $(\mathrm{OxyHb})$. The NIRS used in this study could measure tissue absorbance of light corresponding to three wavelengths (780, 805, and $830 \mathrm{~nm}$ ). The optode was attached to the skin $2 \mathrm{~cm}$ above the frontal midline skull and 1.5 $\mathrm{cm}$ above the eyelids. The distance between transmission and reception was 4 $\mathrm{cm}$. The sampling rate of NIRS was set to $2 \mathrm{~Hz}$. Oxygenation measured by NIRS moreover reflects changes in neural activation in the region of the activated cortical area. [25]. The amount of change (from resting status) in the OxyHb concentration $([\mathrm{OxyHb}]), \Delta[\mathrm{OxyHb}]$, is the most sensitive parameter for brain activity. Therefore, in the present study, $\Delta[\mathrm{OxyHb}]$ was used as an indicator of brain activity [26] [27] [28] [29].

\subsection{Mastication}

In this experiment, a tablet of $0.9 \mathrm{~g}$ of tasteless gum (Meiji Co., Ltd., Saitama, Japan) was used per study participant. The ingredients of the gum are displayed in Table 1. Each subject was instructed to sit in a chair; after sitting for five minutes, he/she performed the U-K Test for $15 \mathrm{~min}$. In total, the U-K Test was performed two times (before and after mastication). After the first U-K Test, subjects took a one-minute rest, followed by five minutes of mastication at three different chewing rates (see below). After a five-minute break, the participant would take the second U-K Test. Mastication frequency was measured using a metronome, and data on mastication frequency were provided in $\mathrm{Hz}$ (i.e., $30 \mathrm{~Hz}$, $70 \mathrm{~Hz}$, and $110 \mathrm{~Hz}$ ). Chewing frequency trials were performed on different days. Each subject participated in three trials. The protocol is shown in Figure 1.

\subsection{Statistical Analysis}

Data were checked first for normality using Shapiro-Wilk test, after which they were analyzed with ANOVA. The results of the U-K Test were calculated based 


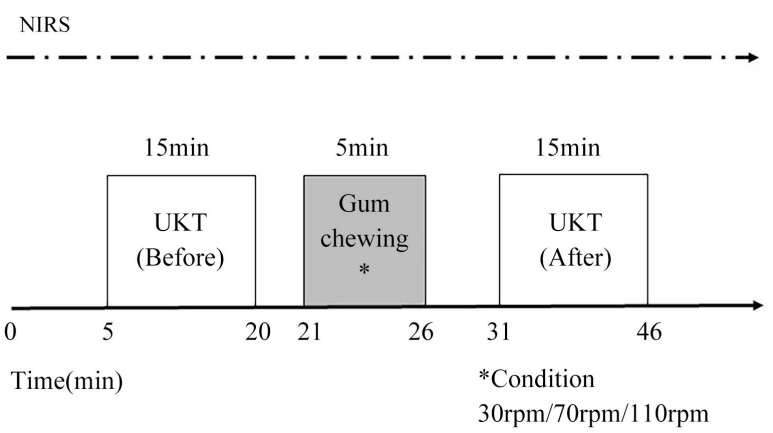

Figure 1. Experimental procedure. While chewing gum for five minutes, the chewing frequency was changed.

Table 1. Ingredient table for gum ( $0.9 \mathrm{~g}$ per grain).

\begin{tabular}{cc}
\hline Composition & Percentage \\
\hline Gum base & 98.5 \\
Lecithin & 1.5 \\
Aspartame acesulfame potassium & - \\
flavoring & - \\
Total & 100 \\
\hline
\end{tabular}

on the number of correct answers achieved per minute for the calculations performed before and after mastication; the average value of the number of correct answers was also calculated. To examine the effect of mastication before and after mastication, including the effect on the U-K Test score, a repeated measure two-way ANOVA was performed.

The value of $\Delta[\mathrm{OxyHb}]$ reflects the relative change within a probe and could not be used in between-probe statistical analyses. In other words, the NIRS data were not absolute and could not be used for comparisons of data obtained before and after chewing. Therefore, a repeated-measures one-way ANOVA was used to study changes in $\Delta[\mathrm{OxyHb}]$ during the computational task.

\section{Results}

\subsection{U-K Test Scores}

The results of the computational task before and after mastication are shown in Figure 2. As seen, no difference was found in the computational task scores between the three mastication frequencies $(\mathrm{F}(2,10)=0.530867 ; \mathrm{p}=0.590837)$. No significant difference was found in U-K Test scores between before and after chewing $(\mathrm{F}(2,10)=0.665166 ; \mathrm{p}=0.417968)$ and no interaction $(\mathrm{F}(2,10)=$ $0.023588 ; \mathrm{p}=0.976726)$.

\subsection{Brain Oxygenation Changes during the U-K Test}

The results of the cerebral oxygenation measurements in the prefrontal cortex during the computational tasks are shown in Figure 3. No significant difference 
was found in oxygenation in the prefrontal area during computational tasks carried out before and after mastication at 30 and $70 \mathrm{~Hz}$ (i.e., $30 \mathrm{~Hz}: \mathrm{F}(1,10)=$ 1.207; $\mathrm{p}=0.298 ; 70 \mathrm{~Hz}: \mathrm{F}(1,10)=2.804 ; \mathrm{p}=0.125)$. However, at $110 \mathrm{~Hz}$, a significant increase occurred in oxygenation after mastication compared with before $(F(1,10)=17.326), p=0.002)$.

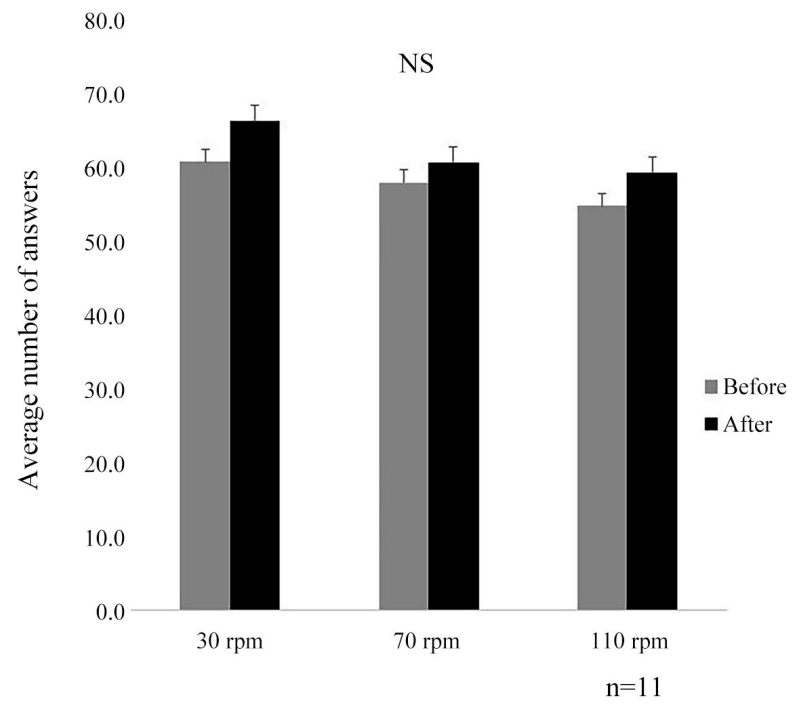

Figure 2. Computational task results based on chewing frequency (average number of answers).


Figure 3. Changes in cerebral blood flow during computational tasks resulting from differences in mastication frequency. The asterisk shows a significant difference $(\mathrm{p}<0.05)$. 


\section{Discussion}

The main result of the present study was that brain activity during performance of the U-K Test did not change after mastication when the chewing frequency was low $(30 \mathrm{~Hz})$ or moderate $(70 \mathrm{~Hz})$. However, when chewing at a high frequency $(110 \mathrm{~Hz})$, brain activity increased significantly. Meanwhile, chewing frequency did not influence the score of computational tasks after tasteless mastication compared with baseline.

In the present study, we used the U-K Test as the calculation task. Subjects were instructed to add random numbers printed on paper for $15 \mathrm{~min}$ and performed a total of two U-K Tests per experiment. Therefore, we speculated that mastication did not enhance cognitive function to the extent prompting changes in U-K Test scores. The discrepancy between elevated brain activity and cognitive performance should be investigated using other cognitive indicators such as the Stroop test.

In the present study, we observed that an increase in chewing frequency was associated with enhanced brain activity during computational tasks. During the 5 min of mastication, all subjects masticated by three different chewing rates (i.e., 30, 70, and $110 \mathrm{~Hz}$ ). In the present study, no significant difference in brain activity was found for the 30 and $70 \mathrm{~Hz}$ trials, but brain activity significantly increased at $110 \mathrm{~Hz}$ compared with the lower mastication rates. This finding is consistent with the results of previous studies on exercise frequency and brain activity [19] [21] [22]. Kuboyama et al. [22] speculated that the rise in frequency also included an element of exertion. In fact, Kuboyama et al. [22] reported a close relationship between integrated electromyography (EMG) and brain activity in exerting muscles.

Mastication is a voluntary, rhythmic movement involving the jaw and masticatory muscles. Rhythmic movement commands come from central pattern generator (CPG) neuronal cell populations, which are mainly located in the brainstem. Jenkins et al. [30] reported that finger tapping at a certain speed and rhythmic chewing movements are generated by brainstem CPGs. Chewing at 70 $\mathrm{Hz}$ is regarded the least conscious effort [25], and researchers speculated that brain activity dose not increase at this mastication rate. However, if mastication is performed at a different speed and frequency, providing exercise commands using CPG alone is not possible; so, in cases in which mastication must be performed with a special consciousness, such as at a high frequency of $110 \mathrm{rpm}$, the presumption exists that the prefrontal cortex is active.

A limitation of the present study is the possibility that the influence of mastication frequency on gum hardness during mastication could have affected the results of this study. In future studies, electromyography (EMG) should be used to study masseter muscle activity as an indicator of the hardness of the gum used. In addition, in the present study, only the aforementioned three chewing frequency conditions were trialed. It would be relevant to consider the chewing movements at frequencies exceeding 110 times/min. 


\section{Conclusion}

This is the first study to date focusing on the association between mastication and potential changes in cognitive function during the performance of computational tasks. The researchers concluded that chewing tasteless gum does not enhance cognitive function sufficiently to change computational task performance.

\section{Conflicts of Interest}

The authors declare no conflicts of interest regarding the publication of this paper.

\section{References}

[1] Ministry of Health, Labour and Welfare (2015) Comprehensive Strategy for Promoting Dementia Measures-Towards the Creation of a Community (New Orange Plan).

https://www.mhlw.go.jp/file/06-Seisakujouhou-12300000-Roukenkyoku/nop1-2_3. pdf

[2] Daviglus, M.L., Bell, C.C., Berrettini, W., Bowen, P.E., Connolly, E.S., Cox, N.J. and Trevisan, M. (2010) NIH State-of-the-Science Conference Statement: Preventing Alzheimer's Disease and Cognitive Decline. NIH Consensus and State-of-theScience Statements, 27, 1-30.

[3] Takeda, S., Matsuzawa, D. and Yamada, K. (1987) Decreased Cerebral Blood Flow and Cerebral Atrophy Due to Aging: The Relation of Contraction. Journal of the American Geriatrics Society, 24, 437-443. https://doi.org/10.3143/geriatrics.24.437

[4] Sakamoto, K., Nakata, H. and Kakigi, R. (2009) The Effect of Mastication on Human Cognitive Processing: A Study Using Event-Related Potentials. Clinical Neurophysiology, 120, 41-50. https://doi.org/10.1016/j.clinph.2008.10.001

[5] Hasegawa, Y., Tachibana, Y., Sakagami, Y., et al. (2013) Flavor-Enhanced Modulation of Cerebral Blood Flow during Gum Chewing. PLoS ONE, 8, e66313. https://journals.plos.org/plosone/article?id=10.1371/journal.pone.0066313 https://doi.org/10.1371/journal.pone.0066313

[6] Sato, A. and Uchida, S. (1996) Neural Regulation of Cerebral Blood Flow and Its Significance. Cardioangiology, 39, 330-337.

[7] Endo, T., Tezuka, S. and Sato, Y. (1982) An Experimental Study of a Preventive Measure against Drowsiness in Car Driving. Journal of Japanese Society for Mastication Science and Health Promotion, 36, 195-204.

[8] Nageishi, Y., Sabashi, K. and Funakoshi, M. (1993) Effect of Gum Chewing on Arousal in a Self-Reported Psychology Test. Journal of Japanese Society for Mastication Science and Health Promotion, 3, 23-26.

[9] Otomaru, A., Kanoya, Y., Watanabe, H., et al. (2003) The Effect of Original Gumdrop Chewing on Psychology Status and Oral Function of Children in an Elementary School. Journal of Japanese Society for Mastication Science and Health Promotion, 13, 67-76.

[10] Suzuki, M., Shibata, M. and Sato, Y. (1992) Energy Metabolism and Endocrine Responses to Gum-Chewing. Journal of Japanese Society for Mastication Science and Health Promotion, 2, 255-262.

[11] Suzuki, M., Ishiyama, I., Takiguchi, T., et al. (1994) Effects of Gum Hardness on Response of Common Carotid Blood Flow Volume, Oxygen Uptake, Heart Rate and 
Blood Pressure to Gum-Chewing. Journal of Japanese Society for Mastication Science and Health Promotion, 4, 9-20.

[12] Chu, N.S. (1994) Effect of Betel Chewing on Performance Reaction Time. Journal of the Formosan Medical Association, 93, 343-345.

[13] Wilkinson, L., Scholey, A. and Wesnes, K. (2002) Chewing Gum Selectivity Improves Aspects of Memory in Healthy Volunteers. Appetite, 38, 235-236. https://doi.org/10.1006/appe.2002.0473

[14] Baker, J.R., Bezance, J.B., Zellaby, E., et al. (2004) Chewing Gum Can Produce Context-Dependent Effects upon Memory. Appetite, 43, 207-210. https://doi.org/10.1016/j.appet.2004.06.004

[15] Stephens, R. and Tunney, R.J. (2004) Role of Glucose in Chewing Gum-Related Facility of Cognitive Function. Appetite, 43, 211-213. https://doi.org/10.1016/j.appet.2004.07.006

[16] Momose, I., Nishikawa, J., Watanabe, T., et al. (1997) Effect of Mastication on Regional Cerebral Blood Flow in Humans Examined by Positron-Emission Tomography with 15O-Labelled Water and Magnetic Resonance Imaging. Archives of Oral Biology, 42, 57-61. https://doi.org/10.1016/S0003-9969(96)00081-7

[17] Onozuka, M., Fujita, M., Watanabe, K., et al. (2002) Mapping Brain Region Activity during Chewing: A Functional Magnetic Resonance Imaging Study. Journal of Dental Research, 81, 743-774. https://doi.org/10.1177/0810743

[18] Takahashi, T., Miyamoto, T., Terao, A., et al. (2007) Cerebral Activation Related to the Control of Mastication during Changes in Food Hardness. Neuroscience, 145, 791-794. https://doi.org/10.1016/j.neuroscience.2006.12.044

[19] Sadato, N., Ibañez, V., Deiber, M.P., et al. (1996) Frequency-Dependent Changes of Regional Cerebral Blood Flow during Finger Movements. Journal of Cerebral Blood Flow \& Metabolism, 16, 23-33. https://doi.org/10.1097/00004647-199601000-00003

[20] Dettmers, C., Lemon, R., Stephan, K.M., et al. (1996) Cerebral Activation during the Exertion of Sustained Static Force in Man. NeuroReport, 7, 2103-2110. https://doi.org/10.1097/00001756-199609020-00008

[21] Kuboyama, N., Nabetani, T., Shibuya, K., et al. (2004) The Effect of Maximal Finger Tapping on Cerebral Activation. Journal of Physiological Anthropology and Applied Human Science, 23, 105-110. https://doi.org/10.2114/jpa.23.105

[22] Kuboyama, N., Nabetani, T., Shibuya, K., et al. (2005) Relationship between Cerebral Activity and Frequency during Maximal Movement Stimulus. Journal of Physiological Anthropology and Applied Human Science, 24, 201-208. https://doi.org/10.2114/jpa.24.201

[23] Byun, K., Hyodo, K., Suwabe, K., et al. (2014) Possible Influences of Exercise-Intensity-Dependent Increases in Non-Cortical Hemodynamic Variables on NIRS-Based Neuroimaging Analysis during Cognitive Tasks. Technical Note. Journal of Exercise Nutrition \& Biochemistry, 18, 327-332. https://doi.org/10.5717/jenb.2014.18.4.327

[24] Miura, H., Tagami, R. and Aoki, S. (2006) Effects of Chewing Frequency on Masseter Muscle Oxygen Dynamics and Common Carotid Artery Blood Flow. Angiology, 46, 21-24.

[25] Yokoyama, T., Sato, M., Natsui, S., et al. (2017) Effect of Gum Chewing Frequency on Oxygenation of the Prefrontal Cortex. Perceptual and Motor Skills, 124, 58-71. https://doi.org/10.1177/0031512516683074

[26] Hoshi, Y., Kobayashi, N. and Tamura, M. (2001) Interpretation of Near-Infrared Spectroscopy Signals: A Study with a Newly Developed Perfused Rat Brain Model. 
Journal of Applied Physiology, 90, 1657-1662. https://doi.org/10.1152/jappl.2001.90.5.1657

[27] Malonek, D., Dirnagl, U., Lindauer, U., Yamada, K., Kanno, I. and Grinvald, A. (1997) Vascular Imprints of Neuronal Activity: Relationships between the Dynamics of Cortical Blood Flow, Oxygenation, and Volume Changes Following Sensory Stimulation. Proceedings of the National Academy of Sciences of the United States of America, 94, 14826-14831. https://doi.org/10.1152/jappl.2001.90.5.1657

[28] Shimada, S., Hiraki, K. and Oda, I. (2005) The Parietal Role in the Sense of Self-Ownership with Temporal Discrepancy between Visual and Proprioceptive Feedbacks. Neuroimage, 24, 1225-1232.

https://doi.org/10.1016/j.neuroimage.2004.10.039

[29] Strangman, G., Culver, J.P., Thompson, J.H. and Boas, D.A. (2002) A Quantitative Comparison of Simultaneous BOLD fMRI and NIRS Recordings during Functional Brain Activation. Neuroimage, 17, 719-731. https://doi.org/10.1006/nimg.2002.1227

[30] Jenkins, I.H., Passingham, R.E. and Brooks, D.J. (1997) The Effect of Movement Frequency on Cerebral Activation: A Positron Emission Tomography Study. Jour nal of the Neurological Sciences, 151, 195-205.

https://doi.org/10.1016/S0022-510X(97)00145-7 